Methods We cluster-randomised 24 low-income neighbourhoods in Lima, Peru, to one of four conditions: (1) Establishment of Community Centers focused on empowerment and promotion of HIV/ STI prevention messages for MSM; (2) Expedited Partner Therapy for bacterial STIs; (3) Both interventions combined or; (4) No intervention. To determine the effectiveness of the interventions, a cohort of participants from each neighbourhood was interviewed concerning sexual risk behaviours and tested for HIV, HSV-2, syphilis, chlamydia and gonorrhoea (pharyngeal and anal) at baseline and 9- and 18-months follow-up visits. We used Poisson regression adjusted for neighbourhood clustering to determine the association of intervention allocation with unprotected anal intercourse (UAI) and overall STI incidence.

Results We enrolled 718 MSM and retained 571 (80\%) at 18 months. At baseline there were no differences by intervention arm in either UAI or STI prevalence. The overall STI incidence was $19 / 100$ person years with no difference in STI incidence by intervention allocation (all p > 0.05) (Table 1). There was an 19\% absolute reduction in reported UAI in all communities comparing baseline to 18 months. There was no difference in the probability of reporting UAI by intervention allocation at the second follow-up (all p > 0.05) (Table 2).

Conclusions There was no significant intervention effect on STI incidence or UAI. Further analyses to interpret the lack of intervention effectiveness are ongoing and should be considered in future efforts to conceptualise and study the relationship between structural and biomedical components of combination prevention.

Abstract P4.122 Table 1 STI incidence during the 18 month follow-up by intervention component.

\begin{tabular}{lll}
\hline & $\begin{array}{l}\text { Community Center vs. } \\
\text { No community Center }\end{array}$ & $\begin{array}{l}\text { Expedited Partner Therapy vs. } \\
\text { No Expedited Partner Therapy }\end{array}$ \\
\hline Any STI incidence & $\begin{array}{l}\text { 18.4 Community Center } \\
\text { 19.7 No Community Center }\end{array}$ & $\begin{array}{l}\text { 23.1 Expedited Partner Therapy } \\
14.0 \text { No Expedited Partner Therapy }\end{array}$ \\
RR & $0.93(95 \% \mathrm{Cl} 0.49-1.76)$ & $1.65(95 \% \mathrm{Cl} 0.85-3.21)$ \\
p-value & 0.42 & 0.07 \\
\hline
\end{tabular}

Abstract P4.122 Table 2 Unprotected anal sex in the past 6 months at the 18 month final study visit

\begin{tabular}{lll}
\hline & $\begin{array}{l}\text { Community Center vs. } \\
\text { No Community Center }\end{array}$ & $\begin{array}{l}\text { Expedited Partner Therapy vs. } \\
\text { No Expedited Partner Therapy }\end{array}$ \\
\hline $\begin{array}{l}\text { Any unprotected sex, } \\
\text { past } 6 \text { months }\end{array}$ & $\begin{array}{l}37.3 \% \text { Community Center } \\
47.9 \% \text { No Community Center }\end{array}$ & $\begin{array}{l}44.3 \% \text { Expedited Partner Therapy } \\
41.8 \% \text { No Expedited Partner } \\
\text { Therapy }\end{array}$ \\
RR & 0.76 & 1.07 \\
& $(95 \% \mathrm{Cl} \mathrm{0.56-1.03)}$ & $(95 \% \mathrm{Cl} 0.79-1.44)$ \\
p-value & 0.07 & 0.66 \\
\hline
\end{tabular}

\section{P4.123 HIV/STI PREVENTION IN MEDICAL PRACTISES: THREE YEARS OF EXPERIENCE WITH A PILOT PROJECT}

doi:10.1136/sextrans-2013-051184.1020

S Taubert, A Schafberger. Deutsche AIDS Hilfe e.V., Berlin, Germany

Background Sexually transmitted infections are often diagnosed too late or not at all. The reason for this may not only be the unspecific or inconspicuous symptoms of many STIs. When it comes to "sexual subjects", both physicians and patients are hesitant to discuss related concerns. This may result in important health risks not being addressed and vital diagnostic measures not being offered.

Methods Strengthening HIV and STI prevention in the healthcare system is the joint objective of an interdisciplinary work group established in 2006, consisting of representatives of the DAGNÄ
[German Association of Practicing Physicians Treating HIV-Infected Patients], the DSTIG [German STI Society], the DAIG [German AIDS Society], the BZgA [Federal Centre for Health Education] and Deutsche AIDS-Hilfe [German AIDS Service Organisation]. Based on a qualitative survey interviewing in 2009, investigating the expectations of physicians and patients for preventive consultations, a further training for physicians was developed.

Results The evaluation of 16 workshops held in 2012 confirmed a central result of the former qualitative survey: The majority saw greatest benefit in workshop modules that allocate opportunities to discuss the correlation between sexual identities, lifestyles and prevention behaviour. Role-playing-units received a particularly positive rating. Basic facts about diagnostic of STIs and information about present-days life of PLWH got a positive voting especially by doctors who do not deal regularly with HIV/STIs. Occasionally, the wish for a structured conversation guide was expressed as well.

Conclusion Our experiences with the trainings leads to the development of a three-pillar model. Firstly: Extending the ability to communicate about sexuality without prejudice as the basic prerequisite for talking about STIs. Secondly: Communicate simple, target group-specific STI diagnostics geared to sexual practises. Thirdly: Offering optional, setting-oriented conversation guides.

\section{P4.124 STI AND LOCAL REGULATION}

doi:10.1136/sextrans-2013-051184.1021

S Warsono. National AIDS Commission, Jakarta, Indonesia

Mimika is one of the districts in the province of Papua, Indonesia. Based on mapping result, the number of sex workers in district of Mimika is 480 people. Unsafe sexual behaviour has led to a high number of HIV cases in Mimika district. To prevent HIV transmission, local governments has open an STI clinic services. However, the number of STI between the sex workers remain high. In 2008, the total number of visits to the STI clinic is 2810 . Of this amount, 616 are positive for STI. In 2009, the total number of visits to the STI clinic is 1550 visits with 531 positive STI cases. While in 2010, the number of visits is 2576 and found 731 cases. On the other hand, AIDS prevention regulations have been made and passed in 2007. One of the contents of these regulations is how to cope with STI by giving penalties for pimps whose sex workers are found to be positive for STI. Looking at the condition, the local government formed a team Chaired by District AIDS Commission to implement the aforesaid local regulation and to do monitoring to its result. The team routinely perform STI test to all sex workers in the site. Should the sex worker is found positive for STI, the penalty is given immediately to the pimp. And if the pimp refuse to pay, then the business site will be closed temporarily until the pimp paid the fine as mandated by the new law. Once the regulation is enforced, there are apparent positive results. In January-March 2012, there were 621 visits to the clinis with only 10 cases of STI. This number is highly significant compared to the STI cases in 2008 and 2010. Thus, local regulation is highly effective in suppressing STI to the sex workers.

\section{P4.125 STRUCTURAL INTERVENTIONS TO REDUCE STIGMATIZATION AND INCREASE UPTAKE OF HIV TREATMENT SERVICES}

doi:10.1136/sextrans-2013-051184.1022

C 0 Nwuba, A Omoloja. Prevention Organizational Systems, AIDS Care and Treatment project, MSH, llorin, Nigeria

Background Stigmatization of persons living with HIV/AIDS (PLWHA) is a major reason for low uptake of HIV screening and treatment services. This paper describes the impact of integration of health services on stigma reduction in Nigeria. 